\title{
O PAPEL DA ASSESSORIA DE IMPRENSA NA GESTÃO DE CRISE DE IMAGEM
}

\section{Gaziela Castilho Cavalaro ${ }^{1}$}

\begin{abstract}
Resumo
O presente artigo apresenta a contribuição que os profissionais de assessoria de imprensa podem oferecer em situação de gestão de crise de imagem. O estudo utiliza metodologia de pesquisa bibliográfica e traz exemplos práticos, com citação de empresas do exterior e do Brasil que já vivenciaram uma crise de imagem e que foram bem-sucedidas, como Johnson \& Johnson, Exxon Valdez, Zara, Rhodia e Telefonica. Os casos foram analisados a partir do embasamento teórico, o que possibilita uma visão mais clara sobre as fases de uma crise de imagem e demonstra como esse fenômeno, com alto potencial destrutivo, pode ser evitado ou revertido.
\end{abstract}

Palavras-chave: Comunicação empresarial, assessoria de imprensa, gestão de crise, planejamento.

\begin{abstract}
The main objective of this article is to introduce a contribution that professional press agents can offer in times of image crisis. In order to do this study, we used bibliographical research methodology and practical examples, by listing foreign and Brazilian companies that underwent an image crisis and succeeded, such as Johnson \& Johnson, Exxon Valdez, Zara, Rhodia and Telefonica. Those cases were analyzed from their theoretical basis, which clearly shows the phases of an image crisis and demonstrates how this potentially destructive phenomenon can be avoided or reverted.

Keywords: Corporate communication, press relations, crisis management, planning.
\end{abstract}

\section{Introdução}

Este artigo objetiva apresentar o papel da assessoria de imprensa na gestão de crise de imagem e propõe uma análise sobre a contribuição que essa atividade profissional oferece para a prevenção ou reversão de uma situação crítica, que põe em risco a reputação e a credibilidade da empresa.

A decisão de realizar este estudo parte da percepção de que escândalos se tornam mais rotineiros na pauta dos diversos veículos de comunicação de massa. Tal realidade, desgastante ou até massacrante para a imagem da empresa que vivencia a crise, tem feito com que as organizações despertem para a importância de utilizar estratégias de comunicação na gestão empresarial a fim de se preservar desse fenômeno.

$\mathrm{O}$ artigo traz metodologia de pesquisa bibliográfica para o embasamento teórico, e exemplos práticos de casos bem-sucedidos de empresas do Brasil e do exterior que já vivenciaram uma crise de imagem. Também é preciso elucidar que a proposta deste artigo busca oferecer uma abordagem no sentido estrito da palavra, conforme bibliografia especializada em crise de imagem, e, por isso, afasta o termo "crise" dos significados triviais e generalistas que percorrem as empresas.

\footnotetext{
${ }^{1}$ Especialista em Comunicação Empresarial pela Universidade Tecnológica Federal do Paraná (UTFPR).
} 


\section{Crise de imagem}

A comunicação no Brasil tem conquistado cada vez mais espaço nas organizações. Matéria publicada no jornal Valor Econômico em outubro de 2011 aponta que os departamentos de comunicação vêm assumindo papel mais relevante, estratégico e atuante em tomadas de decisões nas empresas brasileiras. A conscientização pode ser avaliada a partir de dois fatores: a necessidade de as organizações se comunicarem, de forma ágil e eficaz, tanto com a imprensa quanto com os diferentes públicos, como clientes, fornecedores, funcionários e acionistas; e a inclusão da comunicação no planejamento da empresa para, entre outros itens, desenvolver um Plano de Gerenciamento de Crise, já que a atividade exerce grande contribuição preventiva e reativa caso a organização venha a enfrentar crises de imagem.

É notório que, a partir da segunda metade do século XX, casos de empresas que sofrem exposição negativa na mídia ou entre os públicos de interesse têm se tornado frequentes e cada vez mais abrangentes, especialmente com a chegada da era digital. Nesse contexto, Mário Rosa (2007) explica que as crises de imagem são fenômenos contemporâneos, que ganham força por causa da conformação atual da mídia, da abrangência dos interesses econômicos, da formação de consumidores conscientes e exigentes, da ampla liberdade de debate político. A interligação de tais fatores deixa a preservação da imagem das organizações mais vulneráveis, já que os conflitos podem atingir negativamente a reputação e a credibilidade da empresa a partir de acontecimentos que se desdobram até atingir uma situação extrema, de crise. Por esse motivo, reações adequadas dos diversos setores da organização são necessárias, em especial da assessoria de imprensa, que é uma das áreas que mais cresce em importância na gestão de crise de imagem.

Para se ter ideia, o caso Tylenol, da Johnson \& Johnson (J\&J), um dos mais famosos na história de crise de imagem, conseguiu reverter o quadro negativo e, entre as ferramentas utilizadas para atingir tal resultado, estava a comunicação com a imprensa. O problema ocorreu em 1982, quando alguns comprimidos do analgésico Tylenol foram envenenados com cianeto e vendidos em Chicago. Sete pessoas morreram após ingerir o medicamento e, imediatamente, o Tylenol virou manchete dos jornais e dos noticiários de rádios e televisão, prejudicando bruscamente a imagem da J\&J.

Embora a empresa não tivesse um plano de gerenciamento de crise, conseguiu reagir com medidas assertivas. Na área de comunicação, o jornalista Mário de Moraes afirma, em artigo, que a empresa formou um comitê estratégico de relações públicas para prestar atendimentos dinâmicos a todas as demandas dos veículos de comunicação, atuando com 
transparência na transmissão de informações à opinião pública e, inclusive, pedindo o auxílio da mídia para o alerta de perigo. A empresa também investiu verbas em propaganda para explicar sua versão dos fatos e alegava que os medicamentos tinham sido adulterados, criminosamente, e com isso passava da posição de culpada para vítima.

Outro ponto positivo para a $J \& J$ era a reputação respeitada, construída ao longo de anos, e que foi mantida por causa das decisões assertivas em comunicação e na contenção das causas da crise. Por esses motivos, com oito semanas o analgésico voltou a ser comercializado e, em um ano, o Tylenol recuperou a fatia de mercado que exercia antes do episódio.

Diferente da J\&J, o caso Exxon Valdez não foi tão assertivo. Considerado como um dos maiores desastres ecológicos do mundo, superado apenas pelo caso da Petroleira Britânica (BP), no Golfo do México, o caso Exxon Valdez ocorreu em 1989, quando um navio petroleiro da empresa colidiu com um grande iceberg, no Alaska, provocando o vazamento de 24 mil barris de óleo no mar. O derramamento causou graves problemas ambientais e colocou em risco a saúde da população. A ocorrência ocupou as manchetes e matérias jornalísticas que traziam duras críticas à imagem da Exxon. A situação ficou ainda pior porque a administração da empresa não tinha um plano de gestão de crise de imagem e, para piorar, teve atitudes e reações não satisfatórias tanto da administração quanto do setor de comunicação.

Uma das graves falhas da Exxon foi a demora em se manifestar, já que o presidente da empresa se pronunciou seis dias após o vazamento. Além disso, os executivos tentaram minimizar os efeitos do acidente se esquivando da culpa e se desviando dos prejuízos provocados. Artigo publicado na revista Exame, em 2001, afirma que "um executivo da empresa chegou a dizer que os custos de limpeza no Alasca seriam repassados aos consumidores, na forma de aumento do preço da gasolina."

Em linhas gerais, os diversos erros e acertos cometidos por empresas, ao longo das últimas décadas, em gestão crise de imagem, têm feito os empresários perceberem que nenhum empreendimento está imune a enfrentar tal infelicidade. E, por esse motivo, começaram a surgir análises mais profundas sobre o fenômeno.

Dentre definições esclarecedoras sobre os termos crise de imagem, o manual de comunicação em situações de crise da Pacific Telesis, citado na obra de Dennis Wilcox, Glen T. Cameron e Jordi Xifra (2007), traz um conceito interessante:

Um acontecimento extraordinário, ou uma série de acontecimentos, que afetam de forma adversa a integridade do produto, a reputação ou a estabilidade financeira da organização; ou a saúde e o bem-estar dos trabalhadores, da comunidade, ou do público em geral (p. 325). 
Antes de prosseguir, porém, é importante evitar que o termo "crise de imagem" seja confundido com diversos problemas que uma organização pode enfrentar, como financeira e de relacionamento interno. Uma das propostas deste artigo é, justamente, apresentar o sentido estrito da palavra, conforme bibliografia especializada em crise de imagem. Portanto, vale esclarecer que crise de imagem acontece quando a empresa sofre uma situação negativa que passa a ser conhecida e repudiada pelos públicos de interesse (como funcionários, fornecedores, clientes e comunidade) e que se torna alvo de notícias negativas e cotidianas em diversos veículos de comunicação de massa, prejudicando a reputação da organização.

\begin{abstract}
As crises de imagem constituem um tipo bem particular de crise, diferente de todas as outras que podem atingir líderes ou organizações. Essas crises são potencialmente mais devastadoras porque podem destruir o maior patrimônio de um profissional ou instituição: sua credibilidade. Costumo dizer que pessoas e empresas não vendem serviços ou produtos. O que vendem todos os dias, no mundo inteiro, é confiança. E quando a confiança que os outros depositam em nós deixa de existir, há uma sentença de morte profissional ou empresarial (ROSA, 2007, p.24).
\end{abstract}

Para preservar a credibilidade e a imagem da empresa, teóricos aconselham evitar medidas improvisadas porque aumentam as chances de risco, tornando a empresa ainda mais vulnerável aos efeitos massacrantes de um conflito. E não só as empresas estão sujeitas a enfrentar agravantes na imagem pelo despreparo, mas também personalidades públicas.

Um caso citado por Mário Rosa (2007) é de Eduardo Jorge Caldas Pereira, secretário geral da Presidência da República no primeiro mandato de Fernando Henrique Cardoso. Tudo começou em 1999, com acusações sem evidências que, em pouco tempo, se transformaram em um escândalo que o acusava de desvio de recursos públicos da obra da sede do Tribunal Regional do Trabalho em São Paulo. Para Eduardo Jorge, a experiência foi assustadora. "Em alguns momentos não sabia como nem contra quem lutar” (p. 191). Ele só compreendeu que vivenciava uma crise de imagem quando foi acusado em uma reportagem da revista Veja. “Até aquele momento eu não tinha noção de crise de imagem" (p. 194) e, por isso, reagia de modo improvisado, como se estivesse lidando com um problema do dia a dia. Ao se perceber como protagonista de um escândalo contratou uma assessoria profissional para enfrentar a crise. A partir dessas exemplificações, fica evidente que a regra é preparar-se por meio de um planejamento estratégico.

Mário Rosa (2007) também explica que, embora sejam acontecimentos extraordinários, crises de imagem, geralmente, são precedidas de uma sequência de sinais, que seguem um "certo padrão". Por isso, quando a empresa se mantém em estado de alerta 
preventivo é possível perceber, na maioria das vezes, o conflito na etapa inicial e, assim, reagir com estratégias adequadas para evitar atingir o estágio de crise de imagem ou, pelo menos, reduzir os danos que poderia causar.

Para isso, Mário Rosa (2007) enfatiza a importância da estruturação de um Comitê de Gerenciamento de Crises (CGC), composto pela alta direção e por responsáveis de diversos setores, incluindo a comunicação. A formação do grupo tem o objetivo de desenvolver o Plano de Gerenciamento de Crises (PGC), no qual estão inclusas as seguintes tarefas:

1 - Estabelecer o ranking das crises que uma organização está mais passível de atravessar;

2 - Definir os estágios de cada uma dessas crises, considerando três etapas distintas: a pré-crise, o ápice e o pós-crise. É preciso definir as ações para cada estágio;

3 - Definir o papel de cada integrante do Comitê de Gerenciamento de Crises (CGC) (p. 322).

Rosa alerta ainda que, na prática, é preciso ter habilidade para diagnosticar o surgimento de uma situação de risco. E, neste artigo, o termo "risco" é reportado a situações como desacordos, atitudes repudiadas pela opinião pública, conflitos de interesses ou de ideais e falhas de produção que podem prejudicar alguns dos diversos públicos e provocar um confronto de valores éticos, ambientais, sociais, entre outros. Em linhas gerais, são problemas que têm potencial para aumentar em proporção, resultando ou atingindo o grau de escândalo ou de crise de imagem.

Um exemplo de descuido diante de uma situação de risco ocorreu, recentemente, no Brasil, com a empresa de marca própria Zara. No final de 2011, a marca enfrentou um escândalo por não ter previsto o risco presente na problemática realidade trabalhista de seus fornecedores. Inevitavelmente, uma denúncia foi divulgada na mídia sobre as condições de trabalho, semelhantes à escravidão, praticadas por confecções brasileiras, fornecedoras da Zara. O problema não só provocou respingos, mas uma "tempestade" contra a credibilidade da marca.

Para evitar esses acontecimentos, Mário Rosa (2007) destaca que é fundamental a criação de um mapeamento para que as variáveis de conflitos internas e externas sejam previstas pelo CGC, durante a elaboração do PGC.

Além disso, a prevenção de crise de imagem exige sensibilidade para perceber a evolução, por vezes inevitável, dos conflitos. Se o problema, por exemplo, atingir proporções de escândalo, a empresa precisa saber como e quando aplicar ações durante o desenrolar da crise. Nesse ponto, Dennis Wilcox, Glen T. Cameron e Jordi Xifra (2007) trazem grande 
contribuição ao detalharem a gestão estratégica de crise de imagem em quatro grandes etapas, embora não haja uma linha exata que divida uma fase de outra.

Para os autores espanhóis, a primeira etapa, denominada como fase proativa, é justamente a preventiva, que deve ser realizada de forma contínua pela comunicação e pelos diversos setores da empresa, já que consiste na "análise do entorno" para identificar conflitos, prever problemas, verificar a vulnerabilidade da empresa diante dos conflitos e buscar soluções a fim de evitar ou minimizar uma crise. Nessa fase, a empresa segue rotina normal e, por isso, há condições para reflexões, análises e elaboração de estratégias para o PGC. Além disso, é aconselhável observar constantemente as possíveis falhas da atividade da empresa; levar em consideração as queixas dos diversos públicos; e ler diariamente notícias sobre a empresa e sobre o setor para verificar o teor dos conteúdos publicados.

Se a multinacional Zara, por exemplo, tivesse levado em consideração as notícias emergentes que denunciavam a exploração de trabalhadores praticados por confecções localizadas em países em desenvolvimento, poderia ter se colocado na preventiva, verificando e sanando problemas semelhantes, para evitar ser alvo da mídia. A fase proativa, portanto, é considerada de extrema importância já que "estudos demonstram que a maioria das crises é culpa da própria organização, porque a direção ignora os primeiros sinais de alarme" (WILCOX; CAMERON; XIFRA, 2007, p. 317).

Se, no entanto, a primeira etapa for ignorada ou não for suficiente e variáveis internas ou externas se transformarem em conflitos emergentes, começa a fase estratégica. Nessa etapa, Dennis Wilcox, Glen T. Cameron e Jordi Xifra (2007), explicam que a organização precisa mudar de comportamento, pois a prevenção de danos já exige ações corretivas sobre a causa dos problemas em potencial, bem como medidas de comunicação para informar o público interno e os públicos envolvidos no conflito, como consumidores e fornecedores, sobre os possíveis perigos e ameaças.

Contudo, se, por infelicidade, a situação de risco progredir a ponto de causar um impacto significativo na imagem da organização, Dennis Wilcox, Glen T. Cameron e Jordi Xifra (2007) afirmam que o conflito se transforma em crise de imagem, iniciando a fase reativa. Nesta etapa, o caos quebra a rotina da organização e exige reações imediatas e contínuas de todos os setores específicos que compõem o CGC. O objetivo é solucionar os conflitos e amenizar os ataques à imagem da organização. Nesse processo, é essencial "satisfazer as necessidades dos públicos, como as vítimas de um desastre, os empregados, e os meios de comunicação" (WILCOX; CAMERON; XIFRA, 2007, p. 310). 
As medidas emergenciais objetivam abrandar os julgamentos da opinião pública, que, naturalmente, analisam os valores considerados corretos pela sociedade, elencando o vilão e o mocinho da história noticiada. A tarefa, portanto, é prestar informações e esclarecimentos, demonstrando coerência ao expressar os valores da organização à imprensa e aos públicos envolvidos.

Quando, enfim, os conflitos são solucionados e a organização deixa de incomodar ou provocar riscos aos diversos públicos e de ser alvo da imprensa, a crise se finda, mas as ações estratégicas continuam porque começa a fase de gestão da reputação. De acordo com Dennis Wilcox, Glen T. Cameron e Jordi Xifra (2007), esta é a última etapa e consiste em "uma investigação sistemática para averiguar qual é a situação da reputação da organização e dar os passos necessários para melhorá-la” (WILCOX; CAMERON; XIFRA, 2007, p. 310). Após esse processo, a organização recomeça o ciclo preventivo, que é a fase proativa.

Embora o conhecimento das etapas de uma crise contribua significativamente para a reversão do evento crítico, os autores espanhóis vão além e alertam que, em muitos casos, a decisões tomadas em situação de crise dependem de fatores específicos do momento. Esse conceito, denominado Teoria Contingente da Gestão de Conflitos, aponta que mesmo em posse de um planejamento para cada tipo possível de crise, medidas podem sofrer mudanças em função das circunstâncias.

A gestão de crise, portanto, é um processo sutil, mas que não descarta o preparo antecipado, já que o planejamento serve de aprendizado e é composto por estratégias fundamentais para direcionar ações em meio ao caos.

\section{Assessoria de imprensa}

A assessoria de imprensa é um dos ramos especializados da comunicação social que, em uma definição resumida, tem como função principal estabelecer troca de informações com a sociedade por meio do relacionamento entre a organização e os veículos de comunicação. A tendência, no mundo, é que a atividade se torne ainda mais valorizada, deixando de ser considerada apenas como apoio de comunicação para integrar as decisões de gerenciamento das empresas.

No Brasil, a Rhodia foi a primeira empresa a implantar comunicação com foco estratégico em assessoria de imprensa. As mudanças tiveram início em 1980, quando executivos da organização começam a repensar o caráter estratégico e a política de comunicação da empresa. Para isso, criaram um comitê executivo que analisou o 
macroambiente, na época, caracterizado por redemocratização, nacionalismo nascente, consumidor crítico e exigente, sindicatos mais atuantes, consciência ecológica, entre outros. Com a reflexão, os dirigentes perceberam que a Rhodia não estava acompanhando as mudanças externas e que outras companhias, bem menos importantes, apareciam mais no mercado e eram mais conhecidas. A partir de então, os dirigentes formaram uma equipe de assessoria de imprensa e iniciaram um processo de adaptação externa e de integração interna, no qual adotaram a postura de postas abertas à sociedade por meio do investimento em comunicação e relacionamento com a mídia.

O jornalista Manuel Carlos Chaparro lista características que fortalecem, cada vez mais, uma assessoria de imprensa:

\footnotetext{
Os objetivos deixam de ser a simples exposição na mídia para incorporar a noção de posicionamento estratégico da organização junto ao público interno e à sociedade, seja com fins mercadológicos, de informação ou, simplesmente, imagem (CHAPARRO, apud DUARTE, 2006, p. 236).
}

Para que, nesse processo de mudanças, a Rhodia fosse favorecida não só pela mídia, mas também pela cultura organizacional - isto é, pela adequação de hábitos, posicionamentos e comportamentos dos funcionários, de modo a viabilizar o fluxo de informação -, em 1985, a organização desenvolveu um Plano de Comunicação Social a fim de esclarecer detalhada e simplificadamente todos os procedimentos da nova medida estratégica. O material, bemsucedido, se tornou um clássico por ser o primeiro programa de comunicação empresarial produzido no País, servindo de consulta para empresas brasileiras.

Nesse período de estruturação da comunicação, no entanto, a Rhodia vivenciou uma situação de risco e, pela falta de experiência, acabou enfrentando uma crise de imagem. Tratase do caso Samaritá, em que a Rhodia comprou a Clorogil S.A, em 1976, antes mesmo da política de portas abertas. O problema é que, havia dez anos, a fabricante de produtos químicos lançava resíduos altamente tóxicos em vários pontos da Baixada Santista. A Rhodia percebeu esse passivo ecológico, mas não fez nada a respeito.

Neste ponto, e de acordo com Dennis Wilcox, Glen T. Cameron e Jordi Xifra (2007), a Rhodia comete o primeiro erro, pois ao adquirir a Clorogil S.A e, principalmente, ao perceber o passivo ambiental, já se deparava com a fase estratégica por tratar-se de um problema emergente e com variáveis que poderiam afetar negativamente a organização, como a contaminação da população por vazamento de produtos tóxicos, que de fato ocorreu. Diante da gravidade do problema, o recomendável seria aplicar ações corretivas e, por meio da 
assessoria de imprensa, prestar esclarecimentos e informações à população sobre os perigos dos produtos químicos e sobre como evitar a contaminação.

Apesar desses agravantes, somente dois anos depois, em 1978, a Rhodia decidiu aplicar medidas de correção ao desativar a unidade que contaminou a população da Baixada Santista, e investiu milhões em um incinerador, que não foi colocado em funcionamento e, por consequência, não se desfaz do passivo ecológico. Em 1979/80, a opinião pública começou a se manifestar e, segundo Célia Valente e Walter Hori (1991), a partir de 1985, as queixas se tornaram mais frequentes e a população local se organizou. A Rhodia, que nessa época já estruturava o setor de assessoria de imprensa, deveria ter se atentado para esses sinais de alerta contra a imagem da empresa e tomado medidas preventivas, conforme orientam Dennis Wilcox, Glen T. Cameron e Jordi Xifra (2007). Naquele momento, ainda estava em tempo de reverter o quadro, sem desencadear uma situação de crise de imagem. No entanto, a omissão dos profissionais de comunicação e dos executivos da Rhodia persistia, fazendo com que os problemas piorassem gradativamente.

Naquele ano, A Tribuna, considerado como o maior jornal em circulação na Baixada Santista e um dos veículos mais antigos do Brasil (criado em 1894), publicou uma matéria sobre os produtos lançados no meio ambiente. Apesar de a Rhodia não ter sido citada, a publicação motivou a Companhia de Tecnologia de Saneamento Ambiental (Cetesb) a realizar uma investigação, que constatou a contaminação da população local e de frutos do mar, identificando a Clorogil S.A como única responsável. A situação chegava a níveis críticos e a Rhodia, finalmente, começou a reagir, a passos lentos, enviando dois diretores à Baixada Santista para "tomar conhecimento do alcance do problema". Em pouco tempo, porém, a imprensa de Santos já publicava diariamente que a Rhodia era a responsável pelo vazamento de produtos tóxicos na localidade. Note que a empresa ainda estava alheia à gravidade do caso quando já entrava na fase reativa, de crise.

Apesar de ter um Plano de Comunicação Social, os profissionais de comunicação da Rhodia demonstravam despreparo para enfrentar o caso, já que naquela época não se falava em gestão de crise de imagem. Embora houvesse a falta de preparo, a equipe de assessoria de imprensa da Rhodia poderia ter desfrutado das diversas ferramentas básicas, tradicionais e essenciais da atividade a fim de articular ações de comunicação que pudessem trazer resultados positivos.

O clipping, por exemplo, poderia ter sido aplicado logo que a organização identificou o passivo ambiental. Jorge Duarte (2006) explica que o serviço recolhe as matérias em que a 
organização é citada e também acrescenta assuntos de interesse da empresa. Em geral, as assessorias de imprensa fazem o recorte de jornais e revistas, registram as matérias divulgadas em sites (na época, não seria o caso), e fazem relatório das publicações em rádio e televisão. Todo esse material é organizado de forma padronizada e encaminhado para conhecimento dos dirigentes. O objetivo principal é manter a empresa informada para fazer uma análise do entorno, identificando possíveis notícias negativas sobre a organização ou setor.

A partir desse rastreamento, a assessoria de imprensa também poderia ter aproveitado para compor o mailing, que consiste em uma lista de contato (nome, email, telefone, endereço) de veículos de comunicação e de jornalistas que interessam a organização. Por meio dessa lista, o assessor sabe a quem enviar informações ou com quem entrar em contato.

Há ainda o instrumento mais tradicional da assessoria de imprensa, que é o pressrelease. Trata-se de um texto informativo e em formato jornalístico, com assunto considerado de interesse público, mas que apresenta a ótica da organização ou da fonte. O texto é distribuído para a imprensa como sugestão de pauta, mas pode ser divulgado na íntegra e gratuitamente. Esta ferramenta poderia ter sido utilizada pela Rhodia para prestar esclarecimentos à sociedade, informando a população sobre os perigos e ameaças do passivo ambiental e sobre as providências que já estavam preparando para conter as causas do problema.

Outra medida fundamental é o atendimento à imprensa. Para exercer a tarefa com eficácia, Jorge Duarte (2006) destaca que o assessor de imprensa precisa saber lidar com a urgência e a pressão característica do jornalismo diário, já que repórteres precisam ter acesso praticamente imediato a fontes de informações qualificadas. Se o atendimento for constante e adequado, a tendência é que a organização ganhe credibilidade e passe a ser referência de consulta para os jornalistas e, em caso de gestão de potencial de crise, é essencial para amenizar ou até conter o escândalo emergente.

Além dessas atribuições, próprias de assessoria de imprensa, o setor de comunicação também poderia ter atuado por meio de campanhas publicitárias, como fez a Jonhson \& Jonhson, para alertar a população dos perigos e informar as medidas para conter e destruir o passivo ambiental. Os executivos também poderiam ter sido mais ágeis para colocar em prática as providências corretivas e preventivas a fim de resolver o problema e, ainda, conciliar essas medidas ao desenvolvimento de ações de diálogo e de relacionamento com a comunidade para que a Rhodia se posicionasse como uma empresa que tem responsabilidade social. 
No entanto, mesmo com essas alternativas à sua disposição, a Rhodia continuava sem diálogo com a população e, sem critério específico para gerir o caso, os executivos precisaram pensar em uma medida efetiva de urgência. Decidiram, enfim, instalar o incinerador para destruir os resíduos e, em seguida, o assessor de imprensa da organização, Otávio Bueno da Fonseca, se deslocou até a Baixada Santista, se reuniu com repórteres locais e explicou o que seria feito.

Ao ver divulgada a versão da empresa nos veículos de comunicação, a Rhodia, finalmente, percebeu a importância da assessoria de imprensa para reverter o quadro negativo. A partir daí, as atitudes começavam a seguir para um rumo mais assertivo, já que a organização assumiu as responsabilidades, buscou medidas de correção do problema, e começou a prestar informações à comunidade. Aos poucos, a nova postura ganhou a simpatia e a confiança dos repórteres, contribuindo, significativamente, para reverter a situação.

O episódio serviu de aprendizado para a Rhodia. Tanto que procedimentos tomados em situações críticas foram mantidos como ações preventivas. Jorge Duarte (2006) ressalta que, ao findar a crise, é importante exercer, permanentemente, a manutenção do relacionamento com a imprensa por meio de visitas às redações, envio de releases por email, realização de follow - termo utilizado para os telefonemas dirigidos aos jornalistas a fim de destacar assuntos sobre ações positivas realizadas pela empresa-, entre outros.

$\mathrm{O}$ autor também cita outras tarefas que cabem à assessoria de imprensa, como a produção de veículos jornalísticos institucionais (newsletter, rádio interna, noticiário digital, jornal, revista, mural, vídeos institucionais e outros); produção de conteúdo para sites; promoção de treinamentos para fontes; acompanhamento de entrevistas; eventos (divulgação, cobertura e atendimento à imprensa); produção de fotos; coletivas; planejamento; relatórios; produção de manuais e de textos diversos.

\section{Assessoria de imprensa na gestão de crise de imagem}

Semelhante ao caso da Rhodia, em que o sinal de alerta apareceu quando a empresa efetivou a compra da Clorogil S.A, os fatos vivenciados pela Telefonica começaram quando o grupo espanhol venceu leilão para substituir, no Brasil, a estatal Telesp, em 1999. No processo de transição, os espanhóis perceberam que tinham comprado um sistema tecnológico ultrapassado e cheio de problemas. Nesta constatação, já podemos avaliar que a Telefonica, assim como a Rhodia, se deparava, de imediato, com a fase estratégica. 
Um dos motivos do potencial de crise estava na transição de um sistema estatal para o método privado. No contexto brasileiro da época, o processo de privatização gerava insegurança e desconfiança nos diversos públicos, e provocava um forte abalo nos recursos humanos da organização. Além disso, a Telefonica precisava se ocupar com a urgente correção do sistema de serviços, que exigiam novas tecnologias para garantir qualidade. Todo esse processo, logicamente, deveria ser acompanhado por ações de comunicação para esclarecer aos públicos envolvidos (interno e externo) os transtornos que tais mudanças e melhorias iriam provocar por determinado período. No entanto, não havia setor de comunicação estruturado.

As três situações (transição; tecnologia ultrapassada e problemática; e falta de comunicação), sinalizavam o risco emergente, ou seja, a fase estratégica, já que os problemas detectados poderiam aumentar em proporções pela insatisfação e insegurança dos diversos públicos.

Na prática, a empresa não conseguiu atender, de imediato, o "tripé" emergencial e decidiu priorizar a modernização tecnológica e a adequação dos procedimentos, transformando burocracia em agilidade. Com isso, acabou deixando de lado uma importante área de sustentação, que é a comunicação com os diversos públicos e com a imprensa. O resultado veio rápido. A empresa passou a ser campeã de reclamações nos órgãos de defesa do consumidor, recebeu diversas multas da Agência Nacional de Telecomunicações (Anatel), punições do Ministério da Justiça e enfrentou uma Comissão Parlamentar de Inquérito (CPI), que apurava a qualidade do serviço público.

Nessa altura dos acontecimentos, a Telefônica se tornou alvo dos veículos de comunicação e saltou para a fase reativa, em que a crise se instala devido à repercussão negativa entre os diversos públicos e a mídia, quebrando a rotina da organização e exigindo reações imediatas. Para enfrentar o caos, a Telefonica decidiu contratar a empresa Máquina da Notícia para executar um plano de comunicação emergencial em assessoria de imprensa.

A primeira atitude da terceirizada foi identificar o motivo da crise e as falhas de comunicação. Nesse processo de apuração e análise, Maristela Maffei, sócia-diretora da agência de comunicação, observa que a crise da Telefonica não eclodiu, necessariamente, pela indispensável reestruturação da qualidade e modernização do serviço, mas, sim, pela falta de uma gestão de imagem que, ao deixar a população no desconhecimento do processo de reestruturação, provocou a ira dos consumidores. Era, portanto, o momento de sanar, imediatamente, o problema da desinformação, tanto interna quanto externa. 
A segunda medida foi iniciar um plano de comunicação de emergência, pois era preciso tomar decisões de forma imediata e sob pressão. Para isso, a Máquina de Notícias montou uma estrutura física para o setor de comunicação nas dependências da Telefonica e contratou recursos humanos. A agência também definiu um porta-voz para falar em nome da empresa, buscou conquistar a confiança dos executivos ao explicar as ações que seriam necessárias, e estabeleceu a estratégia de agir com transparência e seriedade.

Antes de prosseguir, porém, é interessante aproveitar esse ponto do estudo para destacarmos a importância das atribuições acima citadas, que são próprias de uma assessoria de imprensa e, especialmente, úteis em uma situação de gestão de crise. Em relação à escolha do porta-voz, Jorge Duarte (2006) destaca alguns critérios:

[...] eleger um único porta-voz, que passe credibilidade, tenha treinamento para lidar com a imprensa e conheça profundamente a própria empresa e o problema. Ao definir esse porta-voz, optar de preferência por alguém que tenha domínio e controle sobre o negócio da empresa; habilidade para ouvir; expressar-se; para manter-se calmo sob forte pressão; postura e boa aparência e, mais importante, transpire credibilidade (DUARTE, 2006, p. 375).

Em situações de emergência, como ocorreu com a Telefonica, talvez não haja um executivo ou profissional que tenha participado de treinamento para lidar com a imprensa, como sugere Jorge Duarte. Nesse caso, é interessante avaliar e selecionar a pessoa que tenha habilidade comunicativa porque tal característica é fundamental para a transmissão de credibilidade, tendo em vista que a aquisição de conhecimentos sobre o negócio ou sobre o problema em questão pode ser mais fácil de adquirir do que desenvolver, imediatamente, a habilidade de se comunicar bem.

Mário Rosa também aponta que a assessoria de imprensa deve orientar o porta-voz para não utilizar jargões técnicos, sempre informar fatos, evitar hipóteses ou especulações, ter boa vontade com a mídia, ser disponível, não privilegiar alguns veículos ou jornalistas em detrimento de outros, nunca falar em off, demonstrar preocupação, nunca dizer "nada a declarar", saber admitir erros, manter o foco no público, associar o discurso com os valores considerados corretos pela sociedade, entre outros fatores que favorecem a administração da crise.

Quanto à conquista da confiança dos executivos, o estabelecimento de uma postura de transparência e seriedade, e a construção da credibilidade junto à imprensa, o correto, de acordo com Forni (2006), é que esses itens sejam obtidos a partir de um trabalho constante de 
assessoria de imprensa. Entretanto, "deve-se reconhecer também que passado e credibilidade não imunizam ninguém contra a crise", mas trata-se de "um capital acumulado ao longo do tempo e que pode ser um ativo muito importante na hora em que um episódio negativo" surgir.

No caso da Telefonica, que acabara de chegar ao Brasil, não houve tempo para a construção de credibilidade ou para a preparação adequada de um porta-voz. Tudo era emergencial e, na verdade, a empresa já tinha demorado demais para atender a imprensa. Por isso, a primeira medida da Máquina da Notícia em atendimento aos veículos de comunicação “foi pedir desculpas a população e dar satisfação" (ROSA, 2007, p. 296). Maristela Maffei também conta que, estrategicamente, ofereceram atenção especial às rádios, porque estas davam espaço para a Telefonica responder as reclamações e alimentavam pauteiros de jornais e televisão. A empresa passou ainda a prestar esclarecimentos para os diversos públicos, como funcionários, lideranças políticas, entre outros.

A Telefonica, finalmente, conduzia o serviço pelo caminho certo, que é o atendimento às demandas da imprensa. Inclusive, não seria exagero dizer que esta é a atitude prioritária em todas as fases de uma crise e até em tempos de normalidade. Para ter eficácia, porém, os profissionais de comunicação e fontes precisam atuar com muita agilidade, principalmente em situação de crise, senão os veículos buscam outras fontes de informações para comentarem o caso, o que favorece a desinformação, piorando o quadro crítico.

A tarefa não é a das mais simples, já que em meio ao caos surge uma avalanche de demandas de imprensa para serem atendidas. Por isso, além de estratégia, Maffei (2007) destaca que é preciso ter sensibilidade:

Para colocar em funcionamento um plano de gerenciamento de crise é preciso entender de estratégia de comunicação, mas também ter sensibilidade para saber quando é importante interromper uma reunião do conselho para colocar o presidente da empresa para falar ou quando o porta-voz resolve a questão. O papel de uma assessoria é operar esse plano com garra e competência, no timing correto, conciliando os interesses do seu cliente com as demandas da mídia e da população. (ROSA, 2007, p. 291).

Embora a tendência da maioria das empresas que enfrentam o caos é focar no atendimento à imprensa, por tratar-se de um fenômeno com grande repercussão, Forni (2006) lembra que o público interno também merece a devida atenção. Ele frisa, inclusive, que "o público interno deveria ser o primeiro a saber" (DUARTE, 2006, p.380). De acordo com o teórico, a comunicação rápida com os colaboradores é essencial para evitar mal-estar, boatos, 
desinformação e até de estimular retaliação por indivíduos que possam estar insatisfeitos com a empresa.

No caso Telefonica, a comunicação interna também foi falha, inicialmente. E, se já não bastasse toda a situação de crise, a organização teve de enfrentar ataques de alguns fornecedores, "que perderam privilégios com a privatização e, por isso, tentavam prejudicar a Telefonica" (ROSA, 2007, p. 303). Diante de mais um obstáculo, a assessoria de imprensa, que já estava empenhada em um trabalho desgastante e incansável para a reversão do quadro negativo, pediu o auxílio da área jurídica para se posicionar com eficácia e, aos poucos, a imprensa percebeu que muitas denúncias eram falsas.

Apesar das grandes proporções da crise, surpreendentemente e em curto espaço de tempo, os resultados positivos de todo o trabalho emergencial da assessoria de imprensa começou a aparecer. "Já no primeiro mês a mídia negativa foi reduzida em $50 \%$. No segundo mês, a redução chegou a 75\%" (ROSA, Mário, 2007, p. 303). A fase mais crítica da crise, portanto, se findava e a Máquina da Notícia teve a sensibilidade de perceber o momento favorável para iniciar a fase de gestão da reputação, no qual a busca é por restaurar a imagem da empresa. A estratégia aplicada nesse processo de recuperação foi uma intensa divulgação de releases positivos sobre os serviços que já estavam praticamente em ordem.

Apesar de a Telefonica ter alcançado resultados positivos em meio a um ritmo emergencial e improvisado de ações de comunicação, é importante elucidar que a empresa poderia ter evitado ou pelo menos amenizado a crise se, antes, tivesse a consciência da importância da assessoria de imprensa. Também é importante deixar claro que não são todos os casos de crise que conseguem resultados positivos, principalmente quando não há preparo prévio. A falta de proximidade com conhecimentos sobre gestão de crise de imagem levam os executivos a tomadas de decisões repentinas e, com isso, a empresa tem mais chances de reagir de forma errada, agravando o escândalo em vez de amenizá-lo.

Maristela Maffei compreendeu essas lições com a experiência intensa no caso Telefonica, e destacou que buscou o tempo todo um ponto de distanciamento saudável entre o prestador de serviço terceirizado e a empresa, porque é preciso "estar perto o suficiente para ter condições de gerenciar a crise [...], mas não tão próximo a ponto de [...] se confundir com a própria empresa" (ROSA, 2007, p. 306). Certamente, a sugestão também vale para assessorias de imprensa que são estruturadas na própria organização, ou seja, não terceirizadas. A atividade de comunicação com imprensa precisa desse viés analítico para que a atuação não caia no risco de só defender ou exaltar a empresa, perdendo as características 
jornalísticas de atuar com foco no interesse social. Portanto, manter o equilíbrio entre o lado empresarial e jornalístico é fundamental para que o assessor de imprensa cumpra o seu papel.

A partir do conteúdo exposto, é válido reforçar ainda que cada caso de gestão de crise de imagem exige medidas específicas, embora o evento ofereça características padronizadas, como pudemos perceber nos casos da Rhodia e da Telefonica. Tais semelhanças tornam viável o desenvolvimento de um planejamento e de metodologias para prevenir e preparar as reações em momentos críticos. Empresários que se sujeitam ao risco da improvisação faz a aposta errada e, infelizmente, ainda são muitos. O correto, segundo Mário Rosa (2007) é que a liderança estimule uma cultura de combate aos conflitos da organização e desenvolva um trabalho de comunicação continuado, porque a prevenção e o gerenciamento da reputação em tempos de conflitos são os conceitos chave de toda essa reflexão sobre a atuação da assessoria de imprensa, já que a atividade é decisiva para lidar tanto com a manutenção da imagem e credibilidade, quanto para gerenciar uma crise já instaurada.

\section{Considerações finais}

Um dos aspectos relevantes elucidado desde o início das leituras para a realização deste estudo é que crise de imagem, em muitos casos, aponta sinais de alerta que seguem um "certo padrão" e, por isso, torna-se possível desenvolver e aplicar ações preventivas e corretivas para evitar ou amenizar problemas com potencial de risco ou a crise propriamente dita. Para estabelecer essas ações estratégicas, é válido conhecer as etapas de uma crise que aponta com clareza como o fenômeno normalmente se desenvolve e, assim, formular um Plano de Gerenciamento de Crise para deixar a empresa preparada para essas eventuais incidências, das quais nenhuma organização está imune.

Embora essa constatação já tenha sido apresentada há alguns anos pelos teóricos de gestão de crise, tal esclarecimento ainda é inovador porque contribui para a quebra do paradigma de que crise acontece somente em situação extraordinária, isto é, sem ser prevista ou esperada. O fato negativo, que chega de surpresa, realmente pode ocorrer. No entanto, estudos apontados pelos teóricos espanhóis mostram que a maioria das organizações ainda enfrenta crises por não se atentar aos primeiros sinais de alerta. Portanto, percebemos que as empresas ainda falham ou desconhecem esse aspecto.

Se, porém, a empresa desenvolve um Plano de Gerenciamento de Crise e mantém o estado de alerta, estará mais preparada para as ações preventivas, corretivas e reativas, nas quais a assessoria de imprensa, de fato, presta grande contribuição. Os casos citados 
comprovam na prática essa afirmação, já que os bons resultados vieram a partir do momento em que as organizações se renderam à importância da comunicação e do relacionamento entre empresa e mídia para o processo de reversão da crise. Nos casos da Exxon Valdez e da Rhodia, que são exemplos de apoio no artigo, e da Telefonica, que é o objeto de análise deste trabalho, as medidas de comunicação foram aplicadas quando já estava em meio aos ataques à sua reputação. É possível observar que a atitude de postergar ações de comunicação em casos com potencial de crise só levam ao agravamento dos transtornos e prejuízos.

Outro ponto relevante foi compreender que a imagem e credibilidade são os patrimônios mais importantes das empresas. Por esse motivo, é válida a realização de um trabalho de assessoria de imprensa continuado para que, quando surgir algum fator de risco, esse ramo da comunicação social já esteja estruturado e com um bom relacionamento com as redações. Tanto em momento de normalidade quando em situação crítica, a assessoria de imprensa deve agir estrategicamente na prestação de informações aos diversos públicos da organização, já que a percepção que as pessoas têm da empresa é o que constrói a sua imagem.

(Artigo recebido em 18/07/2013, aprovado em 10/11/2013).

\section{Referências}

CHAPARRO, Manuel Carlos. Cem anos de assessoria de imprensa. In: Duarte, Jorge (org.). Assessoria de imprensa e relacionamento com a mídia: teoria e técnica. $2^{\mathrm{a}}$ ed. São Paulo: Atlas, 2006.

CORREA, Cristiane. Para sair do pesadelo. Exame, São Paulo, abr. 2001, p. 44, 45.

Disponível em: <http://www.portal-

rp.com.br/bibliotecavirtual/relacoespublicas/administracaodecrises/0116.htm $>$. Acesso em 2 abr. 2012.

DRSKA, Moacir. Área de comunicação conquista relevância em decisões empresariais. Valor Econômico, São Paulo. 7 out. 2011, p. A2.

DUARTE, Jorge. Assessoria de imprensa no Brasil e Produtos e serviços de uma assessoria de imprensa. In: Duarte, Jorge (org.). Assessoria de imprensa e relacionamento com a mídia: teoria e técnica. $2^{\mathrm{a}}$ ed. São Paulo: Atlas, 2006.

FORNI, João José. Comunicação em tempo de crise. In: Duarte, Jorge (org.). Assessoria de imprensa e relacionamento com a mídia: teoria e técnica. $2^{\text {a }}$ ed. São Paulo: Atlas, 2006. 
KOIKE, Beth. Com imagem abalada, Zara é alvo de ação em PE. Valor Econômico, São Paulo. 16, 17 e 18 set. 2011, p. B8.

MORAES, Mário de. Caso Tylenol: um (bom) exemplo de RP. Disponível em:

$<$ http://www.portal-

rp.com.br/bibliotecavirtual/relacoespublicas/administracaodecrises/0089.htm $>$. Acesso em 2 abr. 2012.

ROSA, Mário. A era do escândalo: lições, relatos e bastidores de quem viveu as grandes crises de imagem. $4^{\mathrm{a}}$ ed. São Paulo: Geração, 2007.

VALENTE, Célia e HORI, Walter. Portas Abertas. São Paulo: Best-Seller, 1991.

WILCOX, Dennis; CAMERON, Glen T.; XIFRA, Jordi. Relaciones publicas: estratégias y tácticas. Madrid: Pearson Educación, 2007. $8^{\mathrm{a}}$ ed. 